\title{
The importance of early referral for the treatment of chronic kidney disease: a Danish nationwide cohort study
}

\author{
Kristine Hommel ${ }^{1,2^{*}}$, Mette Madsen ${ }^{3}$ and Anne-Lise Kamper ${ }^{1}$
}

\begin{abstract}
Background: Many patients with advanced chronic kidney disease are referred late to renal units. This is associated with negative aspects. The purpose of the present study was to characterize late versus early referrals for renal replacement therapy including their renal disease, health care contacts and medical treatment before renal replacement therapy (RRT) and the consequences for RRT modality and mortality.

Methods: Nationwide cohort study including 4495 RRT patients identified in the Danish Nephrology Registry 1999-2006. The cohort was followed to end 2007 by linkage to other national registries. Late referral: follow-up $\leq 16$ weeks in renal unit before RRT start. Cox proportional hazards models were used to estimate the relative risk of mortality or waiting list status within 365 days in late referrals versus early referrals.

Results: A total of 1727 (38\%) incident RRT patients were referred late. Among these, 72\% were treated in non-nephrology hospital departments and $91 \%$ in general practice 2 years to 16 weeks before RRT start. Fewer late referrals received recommended pre-RRT treatment as judged by renin-angiotensin-system blockade: 32\% versus $57 \%$ or the D-vitamin analogue alfacalcidol: $5 \%$ versus $30 \%(P<.001)$. Primary RRT modality was peritoneal dialysis: $18 \%$ in late versus $32 \%$ in early referrals $(P<.001)$, $7 \%$ versus $30 \%$, respectively, had an arteriovenous dialysis-fistula $(P<.001)$ and $0.2 \%$ versus $6 \%$ were on the waiting-list for renal transplantation $(P<.001)$ before RRT start. One-year-mortality was higher in late referrals: hazard ratio 1.55 (Cl 95\% 1.35-1.78). In a subgroup, $30 \%$ (Cl 95\% 25-35\%) late and 9\% (Cl 95\% 6-12\%) early referrals had plasma creatinine $\leq 150 \%$ of upper reference limit within 1 to 2 years before RRT start $(P<.001)$.

Conclusions: Late nephrology referrals were well-known to the healthcare system before referral for RRT start and more often had near normal plasma creatinine levels within 2 years before RRT start. They infrequently received available treatment or optimal first RRT modality. An increased effort to identify these patients in the healthcare system in time for proper pre-dialysis care including preparation for RRT is needed.
\end{abstract}

Keywords: Chronic kidney failure, Epidemiology, Late diagnosis, Treatment, Renal replacement therapy

\section{Background}

Treatment of advanced chronic kidney disease (CKD) includes renoprotective therapy, prevention of CKDrelated complications and preparing for chronic renal replacement therapy (RRT). It is well-known that late referral of CKD patients to renal units is associated with

\footnotetext{
* Correspondence: mmadsen@sund.ku.dk

'Department of Nephrology, Rigshospitalet, Copenhagen University Hospital, Blegdamsvej 9, Copenhagen East 2100, Denmark

${ }^{2}$ National Institute of Public Health, University of Southern Denmark, Øster

Farimagsgade 5A, Copenhagen K 1353, Denmark

Full list of author information is available at the end of the article
}

several negative aspects such as increased mortality; although many studies are limited by a lack of data on the history of CKD progression in individuals before RRT start [1-12]. However, late referral still remains a major problem.

To establish a strategy on earlier referral it is important to get information on patients referred late, including their renal disease progression and previous contacts to the health care system. The aim of the present study was to characterize late versus early CKD referrals, their contacts to the health care system before RRT start and

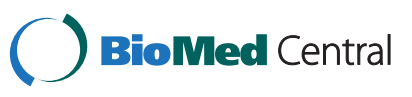


consequences for the treatment. It was a nationwide study offering complete follow-up.

\section{Methods}

The Danish population consisted of 5.3 million persons in 1999 increasing to 5.4 in 2006 [13]. Denmark has a tax-financed universal health care system with free access for all citizens to general practitioners, hospitals and essential operations. During the study period, the number of renal units was 15 . No private dialysis centre's exist.

\section{Patients}

The study population consisted of all 5513 incident chronic RRT patients in 1999-2006 in Denmark, except patients from Greenland and the Faroe Islands or patients without residence permit. Cross-linkage between registries was made with the unique personal identification number assigned to all Danish citizens from birth or immigration.

\section{Data sources}

Information on date of chronic RRT start, modality, renal diagnosis and date of death were obtained from the Danish Nephrology Registry [14], where all patients actively treated for end-stage CKD are registered. Only patients with at least 3 months need of RRT are included in the registry, thereby excluding patients with acute reversible renal failure.

Information on courses in hospital was obtained from the National Patient Registry [15]. This administrative registry contains information on all hospital admissions in Denmark including diagnoses, operations, dates, hospitals and departments since 1977 and from 1995 also information on out-patient treatment. It is mandatory for all hospital departments to report to the registry as reimbursement is based on this information $[16,17]$.

Information on contacts to general practice was obtained from the Danish National Health Service Registry. This administrative registry contains information on all contacts to and services given by general practitioners since 1990 [18].

Information on medical treatment was obtained from the Register of Medicinal Product Statistics of the Danish Medicines Agency. The registry contains information on prescribed and sold drugs since 1994 excluding in-hospital drug use [19].

Information on all patients listed for renal transplantation since 1995 was obtained from the Scandia transplant database [20].

Individual level information on income, highest level of completed education, immigration and ethnic origin was obtained from Statistics Denmark [13].

Level of renal function before RRT start was evaluated in the subgroup of patients with residence in
Copenhagen Municipality 2001-6. Information on plasma creatinine was obtained from databases of the departments of clinical biochemistry in three of four hospitals in Copenhagen and the Laboratory of the General Practitioners in Copenhagen. Data from one hospital was lost with a local change of software. Not all laboratories used plasma creatinine measurement methods standardized or traceable to isotope dilution mass spectrometry (IDMS). Therefore we could not calculate valid estimated glomerular filtration rates with the MDRD [21] study formula. Instead patients were classified according to plasma creatinine level 1-2 years before RRT start: i) plasma creatinine $>150 \%$ of upper reference limit, ii) plasma creatinine $\leq 150 \%$ of upper reference limit or iii) unknown plasma creatinine.

\section{Definitions}

Late referral of patients with CKD was defined as a course in a renal unit starting within 16 weeks or less before RRT start and early referral accordingly as courses starting more than 16 weeks before. Patients who had had a previous course in a renal unit ending more than 2 years before RRT start were classified as late referrals.

In and outpatient courses in any non-nephrology department were studied two years to 16 weeks before RRT start. Some patients had contact to more than one specialty. Courses in cardiology and endocrinology were contained within contacts to departments of internal medicine and equally contacts to urology departments within contacts to any surgical department.

Contacts to general practice were studied two years to 16 weeks before RRT start and patients were classified as: i) patients seen in the clinic, ii) contacts to general practitioner by e-mail or telephone only or iii) no contact to general practitioner.

Pre-RRT renal care was evaluated by medical treatment with renin-angiotensin system (RAS) blocking agents, the vitamin-D analogue alfacalcidol and NSAID judged by prescriptions filled within the period two years to 16 weeks before RRT start. Values of defined daily dose (DDD) were made by the WHO based on an average dose per day for an adult using the drug for the main indication [22]. A minimum of $1: 3$ of the time (206 days) covered by at least $0.25 \mu \mathrm{g}$ of alfacalcidol, $1: 3$ of the time (206 days) covered by a mean of $1 / 2$ DDD of RAS inhibitor or at least $16 \%$ of the time (100 days) covered with a mean of one DDD of NSAID defined the patients treated. One DDD of RAS inhibitor alone or in combination with other drugs equals $10 \mathrm{mg}$ enalapril or $50 \mathrm{mg}$ captopril. One DDD of NSAID equals $1200 \mathrm{mg}$ of ibuprofen.

Comorbidity was evaluated within 2 years before RRT start by ICD-10 diagnose of in and for cancer also 
outpatient hospital course: i) acute myocardial infarction; I22-22, ii) cerebrovascular disease: I60-I64, iii) cancer (excluding non-melanoma skin cancers): $\mathrm{C} 00-43$ and C45-C99 and iiii) bacteraemia: A41-42. Furthermore mean number of inpatient hospital-days and number of visits in general practice within 2 years before RRT start was used as a measure of comobidity.

Income was defined retrospectively as total income in the year 5 years before start of RRT, corrected for inflation according to the price index in Statistics Denmark and grouped into low -, medium- and high corresponding to the level of approximate tertiles in the Danish 2006 population aged 30 to 69 years.

Patients were divided into 3 groups according to the highest level of completed education: i) primary school, ii) high school and skilled craftsmen and iii) persons with university degrees, nurses, librarians, school teachers etc.

Ethnic origin was defined according to the patients' and their parents' country of birth and citizenship [13]. Origin was divided into Danish and for immigrants and descendants into western and non-western [23].

Details on definitions of education, income and ethnic origin are described elsewhere [24].

\section{Statistics}

Chi-squared, Fisher's exact and Wilcoxon signed rank sum test were used where appropriate. Logistic regression was used to compare age, sex, income, education and renal diagnosis in late referrals versus early referrals. Likelihood ratio test for interaction was made for confounder and exposure variables: age, sex, income, education, renal diagnosis and referral. Type 3 test was used to test the effect of income and education. Cox proportional hazards models, with time to death or renal transplantation waiting list status as outcome variables, were used to estimate the relative risk of mortality or waiting list status within 365 days in late referrals versus early referrals. Adjustment was made for differences in age, sex, renal diagnoses, comorbidity and emigration. The proportional hazards assumption was met. All variables were kept in the models regardless of significance level. Analyses were performed using SAS version 9.2, SAS Institute Inc.

\section{Ethical considerations}

The study was approved by the Danish Data Protection Agency. Data was anonymised to ensure privacy of the involved patients.

\section{Results}

Patients from 5 of 15 renal units were excluded because of non-specific classification of hospital departments to the NPR. These included 886 patients $(16 \%)$ of the total 5513 incident RRT patients. A total of 86 patients (2\%) were excluded because of renal diagnoses indicating irreversible acute renal failure: haemolytic uremic syndrome and acute tubular necrosis or age less than one year. Also, 46 patients (1\%) who immigrated within the 2 years before RRT start were excluded. Basic characteristics of the patients included and excluded regarding sex, age and renal diagnoses were similar. The remaining cohort was 4495 patients.

In a total of 4495 patients, 1727 (38\%) were referred late to a renal unit before RRT start and 806 patients (18\%) very late, within 1 week (Table 1 ).

Median age of late referrals and the proportion of patients aged 70 years or more were higher in late compared to early referrals. When adjusting for sex and renal diagnosis, odds ratio (OR) for late referral was 1.29 in patients aged $\geq 70$ years compared to $<70$ years $(\mathrm{P}<.001)$ (Table 2). The proportion of women was stable $37-39 \%$ in total and among the 70 year olds in early and late referrals. Patients with the common renal diagnoses diabetic nephropathy, adult polycystic kidney disease or chronic glomerulonephritis were more frequently early referrals. When adjusting for differences in age and sex, OR for late referral in patients with diabetic nephropathy was 0.62 , chronic glomerulonephritis 0.52 and polycystic kidney disease $0.27 \quad(\mathrm{P}<.001)$ compared to the rest of the patients. There was a significant interaction between age and diabetes as old diabetic patients had a similar risk of late and early referral. Referral pattern was similar in patients aged 30-69 years regardless of length of education $(\mathrm{P}=.14)$ and level of income $(\mathrm{P}=.06)$.

Late referrals had more often been admitted to hospital within 2 years before RRT start because of acute myocardial infarction, stroke or cancer. Also, late referrals had more days in hospital compared to early referrals. There was no difference between the two referral groups in the frequency of bacteraemia.

Among late referrals, 1247 (72\%) had had a course in a non-nephrology department within 2 years to 16 weeks before RRT start (Table 3). These included departments of endocrinology: 116 patients (7\%), cardiology: 160 (9\%) and urology: 121 (7\%). The proportion of patients with a course in a non-nephrology department was lower $(\mathrm{P}<.001)$ in late compared to early referrals. A total of 119 patients (7\%) among late referrals had had a course in a nephrology department which terminated more than two years before RRT start. Totally 1567 late referrals, (91\%) were seen in general practice and 1047 (61\%) had had blood tests done.

Prescriptions of alfacalcidol or RAS blocking agents were filled by fewer late compared to early referrals (Table 4). While there was no difference between late and early referrals filling $\geq 1$ prescription of NSAID, fewer late compared to early were treated with NSAID $\geq 100$ days within 2 years to 16 weeks before RRT start $(\mathrm{P}<.001)$. 
Table 1 Characteristics of late versus early nephrology referrals before renal replacement therapy start

\begin{tabular}{|c|c|c|c|}
\hline & Late referrals ${ }^{a}$ & Early referrals $^{\mathbf{b}}$ & $P$ value \\
\hline Incident RRT patients, $\mathrm{n}$ & 1727 & 2768 & \\
\hline Age, median (IQR) & $67(55-75)$ & $63(52-73)$ & $<.001$ \\
\hline Women, n (\%) & $653(38 \%)$ & $1024(37 \%)$ & .58 \\
\hline Age women, median (IQR) & $68(54-75)$ & $64(51-73)$ & $<.001$ \\
\hline Patients aged $\geq 70$ years, $\mathrm{n}(\%)$ & $720(42 \%)$ & $905(33 \%)$ & $<.001$ \\
\hline Women in patients aged $\geq 70, \mathrm{n}(\%)$ & $278(39 \%)$ & $340(38 \%)$ & .67 \\
\hline Ethnic origin non-western countries ${ }^{c}, \mathrm{n}(\%)$ & 65 (4\%) & $132(5 \%)$ & .11 \\
\hline Ethnic origin western countries ${ }^{\mathrm{d}}, \mathrm{n}(\%)$ & $43(2 \%)$ & $68(2 \%)$ & .94 \\
\hline Diabetic end-stage renal disease ${ }^{\mathrm{e}}, \mathrm{n}(\%)$ & $348(20 \%)$ & $706(26 \%)$ & $<.001$ \\
\hline Adult polycystic kidney diseasef, n (\%) & $57(3 \%)$ & $261(9 \%)$ & $<.001$ \\
\hline Chronic glomerulonephritis $^{9}$, n (\%) & $138(8 \%)$ & $346(13 \%)$ & $<.001$ \\
\hline \multicolumn{4}{|l|}{ Comorbidity } \\
\hline Acute myocardial infarction ${ }^{h}, \mathrm{n}(\%)$ & $99(6 \%)$ & $119(4 \%)$ & .03 \\
\hline Strokei, n (\%) & $81(5 \%)$ & $81(3 \%)$ & .002 \\
\hline Cancer in total', $\mathrm{n}(\%)$ & $216(13 \%)$ & $156(6 \%)$ & $<.001$ \\
\hline Cancer in the urinary tract ${ }^{k}, \mathrm{n}(\%)$ & 49 (3\%) & $34(1 \%)$ & $<.001$ \\
\hline Genital cancer', n (\%) & $41(2 \%)$ & $43(2 \%)$ & .05 \\
\hline Bacteraemia $^{\mathrm{m}}$, n (\%) & $48(3 \%)$ & $62(2 \%)$ & .25 \\
\hline Days in hospital, median $^{\text {n }}$ (IQR) & $28(14-52)$ & $16(5-37)$ & $<.001$ \\
\hline Visits in general practice, median ${ }^{\mathrm{n}}$ (IQR) & $11(5-20)$ & $10(5-19)$ & .08 \\
\hline Patients $30-69$ years, $\mathrm{n}$ & 924 & 1748 & \\
\hline Primary school only, n (\%) & $420(45 \%)$ & $731(42 \%)$ & .07 \\
\hline Low income ${ }^{\circ}, \mathrm{n}(\%)$ & 566 (61\%) & 1001 (57\%) & .05 \\
\hline
\end{tabular}

Abbreviations: RRT, renal replacement therapy; IQR, interquartile range.

atate referrals: Course in a nephrology department $\leq 16$ weeks.

${ }^{b}$ Early referrals: Course in a nephrology department $>16$ weeks.

'Western countries: Andorra, Australia, Canada, EU, Iceland, Monaco, New Zealand, Norway, San Marino, Switzerland, USA and the Vatican State.

${ }^{\mathrm{d}}$ Non-western countries: those not being western countries or Denmark.

eDiabetic end-stage renal disease (ICD-10 E10-E14).

${ }^{\mathrm{f}}$ Adult polycystic kidney disease (ICD-10 Q61).

${ }^{9}$ Chronic glomerulonephritis (ICD-10 N00-N08).

${ }^{\mathrm{h}}$ Admitted to hospital within 2 years before RRT start with ICD-10 diagnoses: 121 or 122.

'Admitted to hospital within 2 years before RRT start with ICD-10 diagnoses: 160, 161, 162, 163 or 164.

${ }^{\mathrm{j}}$ Admitted to hospital or course in outpatient clinic within 2 years before RRT start with ICD-10 diagnoses: C00-C43 or C44-C99.

${ }^{\mathrm{k}}$ Admitted to hospital or course in outpatient clinic within 2 years before RRT start with ICD-10 diagnoses: C64-68.

'Admitted to hospital or course in outpatient clinic within 2 years before RRT start with ICD-10 diagnoses: C51-58 or C61-63.

${ }^{m}$ Admitted to hospital within 2 years before RRT start with ICD-10 diagnoses: A41-42.

${ }^{n}$ Within 2 years before RRT start.

'Low income: $\leq 30,200 €$ per year (33.7\% of the Danes with the lowest income 2006, corrected for inflation).

In total, $314(18 \%)$ late compared to $897(32 \%)$ early referrals started RRT with peritoneal dialysis (Table 5). A lower proportion of late compared to early referrals had an arteriovenous vascular access before RRT start. Fewer late $(8 \%)$ compared to early (21\%) referrals were on the waiting-list for a renal transplant within one year after RRT start. Few patients died while waiting. One-year renal transplantation waiting-list status differed with a hazard ratio of 0.32 (CI 95\% 0.26-0.38) in late compared to early referrals when adjusted for differences of age, sex, renal transplantation within one year, death, emigration, comorbidity and renal diagnoses. Median number of days in hospital 1-60 days after RRT start was higher
$(\mathrm{P}<.001)$ in late: 16 days (interquartile range $6-30)$ compared to early referrals: 4 days (interquartile range 0 15).

A total of $435(25 \%)$ in late referrals died within one year after RRT start compared to 412 (15\%) in early referrals $(\mathrm{P}<.001)$. Mortality within 1 year also differed with a hazard ratio of 1.55 (95\% CI 1.35-1.78) in late compared to early referrals when adjusted for differences of age, sex, emigration, comorbidity and renal diagnoses.

In a total of 370 patients, 114 (31\% CI 95\% 26-36\%) late referrals, with residence in Copenhagen Municipality commenced RRT in 2001-6. In 33 (29\% CI 95\% 24$34 \%)$ of late and 206 (80\% CI $95 \% 76-84 \%)$ of early 
Table 2 Risk of late nephrology referral before start of renal replacement therapy

\begin{tabular}{|c|c|c|}
\hline & OR $(95 \% \mathrm{Cl})$ & $P$ value \\
\hline Patients $\geq 70$ years $^{a}$ & $1.47(1.30-1.67)$ & $<.001$ \\
\hline Patients $\geq 70$ years $^{\mathrm{b}}$ & $1.29(1.13-1.47)$ & $<.001$ \\
\hline Diabetic nephropathy $^{c}$ & $0.62(0.53-0.72)$ & $<.001$ \\
\hline Diabetic nephropathy $\geq 70$ years $^{d}$ & $0.81(0.63-1.05)$ & .12 \\
\hline Diabetic nephropathy $<70$ years ${ }^{\mathrm{e}}$ & $0.54(0.45-0.66)$ & $<.001$ \\
\hline Chronic glomerulonephritis ${ }^{c}$ & $0.52(0.42-0.64)$ & $<.001$ \\
\hline Adult polycystic kidney disease ${ }^{c}$ & $0.27(0.20-0.37)$ & $<.001$ \\
\hline Medium / short education ${ }^{f}$ & $0.93(0.78-1.12)$ & .45 \\
\hline Long / short education ${ }^{f}$ & $0.88(0.67-1.16)$ & .36 \\
\hline Medium / low income ${ }^{g}$ & $0.99(0.81-1.21)$ & .94 \\
\hline High / low income ${ }^{g}$ & $0.77(0.58-1.01)$ & .06 \\
\hline
\end{tabular}

Abbreviations: Late referral, course in a nephrology department $\leq 16$ weeks; $\mathrm{OR}$, odds ratio; $95 \% \mathrm{Cl}, 95 \%$ confidence interval.

aReference group: patients $<70$ years, adjusted for sex.

${ }^{\mathrm{b}}$ Reference group: patients $<70$ years, adjusted for sex and renal diagnoses.

'Reference group: patients with other renal diagnoses than diabetic. nephropathy, chronic glomerulonephritis or adult polycystic kidney disease, adjusted for sex and age.

${ }^{\mathrm{d}}$ Reference group: patients $\geq 70$ years with other renal diagnoses than diabetic nephropathy, chronic glomerulonephritis or adult polycystic kidney disease, adjusted for sex.

e Reference group: patients $<70$ years with renal diagnoses other than diabetic nephropathy, chronic glomerulonephritis or adult polycystic kidney disease, adjusted for sex.

${ }^{f}$ Reference group: patients with short education, adjusted for age, sex, renal diagnoses and income.

${ }^{9}$ Reference group: patients with low income, adjusted for age, sex, renal diagnoses and education.

referrals plasma creatinine was $>150 \%$ of upper reference limit $1-2$ years before RRT start $(\mathrm{P}<.001)$. In $34(30 \%$ CI $95 \% 25-35 \%)$ of late and 22 (9\% CI 95\% 6-12\%) of early referrals plasma creatinine was $\leq 150 \%$ of upper reference limit $(\mathrm{P}<.001)$. While, in 47 (41\% CI 95\% 36-
$46 \%)$ of late and 28 (11\% CI $95 \% 25-31)$ of early referrals we have no information on plasma creatinine 12 years before RRT start $(\mathrm{P}<.001)$.

\section{Discussion}

The present Danish nationwide study, including 4495 incident RRT patients in the period 1999-2006 shows that $38 \%$ of the patients had been referred to a renal unit within 16 weeks before RRT start. This is in accordance with previous reports in smaller studies reporting late referral in $22-40 \%$ of incident RRT patients when defined as a nephrology course starting $\leq 4$ months before RRT start $[1,2,6,7,9,10,12]$. The most important finding in our study is that late referrals were wellknown in the healthcare system before RRT start and yet received insufficient pre-RRT renal care.

The reasons for late referral of well-known patients are not clarified. One explanation might be fast progression of renal disease. Most studies on late referral are limited by lack of data on the history of CKD in individuals before RRT start. In the present study, a subgroup analysis in 370 patients showed that $30 \%$ of late referrals had plasma creatinine $\leq 150 \%$ of upper reference limit within 1-2 years before RRT start. A European and an American study have found that general practitioners were less responsible for late referral than non-nephrology medical specialists $[25,26]$.

The quality of pre-RRT care was evaluated by the use of specific drugs to prevent CKD progression and modify complications as well as the use of a common nephrotoxic agent. The frequency of peritoneal dialysis as primary RRT modality, arteriovenous vascular access in haemodialysis patients and renal transplantation waiting-list status also reflect pre-RRT care. It was found

Table 3 Hospital courses and contacts to general practice according to early or late nephrology referral

\begin{tabular}{|c|c|c|c|}
\hline Courses 2 years to 16 weeks before RRT start & $\begin{array}{l}\text { Late referrals }^{a} \\
n=1727\end{array}$ & $\begin{array}{l}\text { Early referrals } \\
\mathrm{n}=2768\end{array}$ & $P$ value \\
\hline Any non-nephrology department, n (\%) & $1247(72 \%)$ & $2413(87 \%)$ & $<.001$ \\
\hline Endocrinology department, $\mathrm{n}(\%)$ & $116(7 \%)$ & $385(14 \%)$ & $<.001$ \\
\hline Cardiology department, n (\%) & $160(9 \%)$ & $506(18 \%)$ & $<.001$ \\
\hline Any department of internal medicine, $\mathrm{n}(\%)$ & $893(52 \%)$ & $1854(67 \%)$ & $<.001$ \\
\hline Urology department, n (\%) & $121(7 \%)$ & $447(16 \%)$ & $<.001$ \\
\hline Any surgical department, n (\%) & $902(52 \%)$ & $1849(67 \%)$ & $<.001$ \\
\hline Nephrology department, course terminated 2 years before RRT start, $\mathrm{n}(\%)$ & $119(7 \%)$ & & \\
\hline Seen by general practitioner, $\mathrm{n}(\%)$ & 1567 (91\%) & $2633(95 \%)$ & $<.001$ \\
\hline Telephone/e-mail contacts only to general practice, n (\%) & $54(3 \%)$ & $63(2 \%)$ & .08 \\
\hline Not seen by general practitioner, $\mathrm{n}(\%)$ & $106(6 \%)$ & $72(3 \%)$ & $<.001$ \\
\hline Blood tests done in general practice, $\mathrm{n}(\%)$ & $1047(61 \%)$ & $1736(63 \%)$ & .16 \\
\hline Seen in general practice or non-nephrology department & 1605 (93\%) & $2730(99 \%)$ & $<.001$ \\
\hline
\end{tabular}

Abbreviations: RRT, renal replacement therapy; IQR, interquartile range.

atate referrals: Course in a nephrology department $\leq 16$ weeks.

${ }^{b}$ Early referrals: Course in a nephrology department $>16$ weeks. 
Table 4 Medical treatment according to late and early nephrology referral

\begin{tabular}{|c|c|c|c|}
\hline Prescriptions filled 2 years to 16 weeks before RRT start & $\begin{array}{r}\text { Late referrals }^{a} \\
n=1727\end{array}$ & $\begin{array}{r}\text { Early referrals }^{b} \\
n=2768\end{array}$ & $P$ value \\
\hline$\geq 1$ prescription of alfacalcidol, $\mathrm{n}(\%)$ & $100(6 \%)$ & $1129(41 \%)$ & $<.001$ \\
\hline Patients treated with alfacalcidol ${ }^{c}, \mathrm{n}(\%)$ & $82(5 \%)$ & $841(30 \%)$ & $<.001$ \\
\hline$\geq 1$ prescription of RAS blocking agents, $n(\%)$ & $636(37 \%)$ & $1792(65 \%)$ & $<.001$ \\
\hline Patients treated with RAS blocking agents ${ }^{\mathrm{d}}, \mathrm{n}(\%)$ & $548(32 \%)$ & $1567(57 \%)$ & $<.001$ \\
\hline$\geq 1$ prescription of NSAIDs, $\mathrm{n}(\%)$ & $485(28 \%)$ & $712(26 \%)$ & .08 \\
\hline Patients treated with NSAIDs ${ }^{\mathrm{e}}, \mathrm{n}(\%)$ & $166(10 \%)$ & $188(7 \%)$ & $<.001$ \\
\hline
\end{tabular}

Abbreviations: RRT, renal replacement therapy; RAS, renin-angiotensin system; DDD, defined daily dose.

atate referrals: Course in a nephrology department $\leq 16$ weeks.

${ }^{b}$ Early referrals: Course in a nephrology department $>16$ weeks.

${ }^{\mathrm{C}} \mathrm{A}$ minimum of $1: 3$ of the time (206 days) covered by a mean of $0.25 \mu \mathrm{g}$ of alfacalcidol.

${ }^{d}$ A minimum of $1: 3$ of the time (206 days) covered by a mean of $1 / 2$ DDD of RAS inhibitor.

${ }^{\mathrm{e}} \mathrm{A}$ minimum of $16 \%$ of the time (100 days) covered with a mean of one DDD of NSAID.

that fewer late referrals received RAS blocking agents or the D-vitamin analogue alfacalcidol. The use of shortterm NSAID was the same in both referral groups but long-term use was a little higher in late referrals probably reflecting that both groups had significant proportions of patients with chronic pain conditions. Furthermore, late referrals less often commenced RRT with peritoneal dialysis, had an arteriovenous fistula or were on the renal transplantation waiting-list. Previous studies have shown similar results $[1-5,7,9,12]$.

The late referred patients were characterized by older age and more comorbidity. This has also been reported in previous studies $[5,7,9]$. Acute decrease in renal function in old patients with moderate CKD might be a cause. In addition, general practitioners and non-nephrologists might consider old patients with CKD and comorbidity unfit for RRT. Subsequently, when old patients are hospitalized because of severe uremic symptoms, RRT is initiated. However, some studies have found no age differences between early and late referrals $[1,25]$. The different findings might be explained by type 2 error because of small study population size.

In accordance with our findings, previous studies have observed more cancer and cardiovascular disease in late compared to early referrals $[7,10,25,26]$. We used administrative registry data on hospital admissions because of myocardial infarction, stroke or cancer to study comorbidity. Probably, the overall cardiovascular comorbidity in both early and late referrals is underestimated because mild symptoms are treated in general practice.

As reported in other studies $[7,12,25]$, we found that the renal diagnoses diabetic nephropathy, adult polycystic kidney disease and chronic glomerulonephritis were less frequent in late compared to early referrals. Nonnephrology physicians might be more aware of referring patients with well-known renal diagnoses.

Income and education was similar in early and late referrals in our study like in a French study [27]. Generally, persons with low income or short education are as frequent users of the publicly funded health care system in Denmark as persons with higher income and longer education[28]. In contrast, socially deprived patients in UK and patients with shorter schooling in France, Italy and Switzerland were more often referred late [25,29].

In accordance with our findings, one-year mortality adjusted for comorbidity was higher in late compared to early referrals $[7,12]$. This was also true when excluding lead-time bias [30]. In one study, no difference in oneyear survival was found [10]. However, late referrals were younger than early referrals and analyses were

Table 5 Dialysis modality, access and renal transplantation waiting list status in late and early referralsw

\begin{tabular}{|c|c|c|c|}
\hline & $\begin{array}{r}{ }^{\mathrm{a}} \text { Late referrals } \\
\mathrm{n}=1727\end{array}$ & $\begin{array}{r}{ }^{b} \text { Early referrals } \\
n=2768\end{array}$ & $P$ value \\
\hline Peritoneal dialysis as first RRT modality, $\mathrm{n}(\%)$ & $314(18 \%)$ & $897(32 \%)$ & $<.001$ \\
\hline Haemodialysis as first RRT modality, n (\%) & $1403(81 \%)$ & $1743(63 \%)$ & $<.001$ \\
\hline Arteriovenous vascular access before RRT start, n (\%) & $118(7 \%)$ & $841(30 \%)$ & $<.001$ \\
\hline On transplantation waiting-list before RRT start, n (\%) & $4(0.2 \%)$ & $177(6 \%)$ & $<.001$ \\
\hline Transplanted within one year after RRT start, n (\%) & $63(4 \%)$ & $279(10 \%)$ & $<.001$ \\
\hline On transplantation waiting-list within one year after RRT start, n (\%) & $144(8 \%)$ & $582(21 \%)$ & $<.001$ \\
\hline Death on the waiting-list within one year after RRT start, n (\%) & $2(0.1 \%)$ & $8(0.3 \%)$ & .33 \\
\hline
\end{tabular}

Abbreviations: RRT, renal replacement therapy.

atate referrals: Course in a nephrology department $\leq 16$ weeks.

${ }^{b}$ Early referrals: Course in a nephrology department $>16$ weeks. 
adjusted for albuminaemia which has been shown to be a strong predictor of death and associated with late referral in incident dialysis patients [10,31].

The nationwide administrative and clinical registries used in this study offer complete sources of data as all citizens have free access to the tax-financed health care system. The validity of data including the date of RRT start in and completeness of the Danish Nephrology Registry is good [32]. Also, information in the National Patient Registry is assumedly valid and gives the possibility of complete follow-up [15-17], thus, the risk of misclassification bias of late or early referrals should be small.

Different definitions of late referral have been used in the literature: $1,3,4$ or 6 month or level of serum creatinine $[1,2,5,7,9,10,12,25]$. The time needed to prepare for chronic dialysis is at least 3-4 months.

We only had information on plasma creatinine before RRT start in a subgroup of patients. Thus, the generalisability of the results depends on similarities of CKD progression in these patients compared to other patients. Late nephrology referral is of course unavoidable for patients with irreversible acute renal failure or rapidly progressive renal failure. Irreversible acute renal failure has been reported to constitute $11-38 \%$ of late referrals $[1,10]$.

The retrospective design of this study only sheds light on the courses of patients starting active treatment of renal failure and not the ones receiving conservative treatment as we have no information on non-referrals. A prospective study, identifying persons with CKD by plasma creatinine, would provide additional information.

\section{Conclusion}

Late nephrology referrals were well-known to the healthcare system before referral to renal units and more often had near normal levels of plasma creatinine within two years before RRT start. They infrequently received available treatment or optimal first RRT modality. More attention on referral of CKD patients from general practice and non-nephrology hospital departments to renal units is recommended.

\section{Competing interest}

No competing interests to declare.

\section{Authors' contributions}

AK, MM and KH contributed to conception, design and acquisition of data as well as analysis and interpretation of data. KH drafted the manuscript. AK, $\mathrm{MM}$ and $\mathrm{KH}$ were all involved in revising the manuscript critically for important intellectual content and have given final approval of the version to be published.

\section{Acknowledgements}

The study was supported by grants from the Augustinus Foundation, the Danish Society of Nephrology, the Danish Kidney Association, the Tryg Foundation and the Helen and Ejnar Bjørnow Foundation. We would like to thank staff at the departments of clinical biochemistry in Bispebjerg,
Hvidovre and Rigshospitalet Copenhagen University Hospital as well as the Laboratory of the General Practitioners in Copenhagen for their invaluable help. Also, thanks to the Scandiatransplant database.

\section{Author details}

${ }^{1}$ Department of Nephrology, Rigshospitalet, Copenhagen University Hospital, Blegdamsvej 9, Copenhagen East 2100, Denmark. ${ }^{2}$ National Institute of Public Health, University of Southern Denmark, Øster Farimagsgade 5A,

Copenhagen K 1353, Denmark. ${ }^{3}$ Department of Public Health, University of Copenhagen, Øster Farimagsgade 5, Copenhagen K 1014, Denmark.

Received: 11 April 2012 Accepted: 31 August 2012

Published: 10 September 2012

\section{References}

1. Arora P, Obrador GT, Ruthazer R, Kausz AT, Meyer KB, Jenuleson CS, et al: Prevalence, predictors, and consequences of late nephrology referral at a tertiary care center. J Am Soc Nephrol 1999, 10:1281-1286.

2. Astor BC, Eustace JA, Powe NR, Klag MJ, Sadler JH, Fink NE, et al: Timing of nephrologist referral and arteriovenous access use: the CHOICE Study. Am J Kidney Dis 2001, 38:494-501.

3. Avorn J, Winkelmayer WC, Bohn RL, Levin R, Glynn RJ, Levy E, et al: Delayed nephrologist referral and inadequate vascular access in patients with advanced chronic kidney failure. J Clin Epidemiol 2002, 55:711-716.

4. Cass A, Cunningham J, Snelling P, Ayanian JZ: Late referral to a nephrologist reduces access to renal transplantation. Am J Kidney Dis 2003, 42:1043-1049.

5. Goransson LG, Bergrem $\mathrm{H}$ : Consequences of late referral of patients with end-stage renal disease. J Intern Med 2001, 250:154-159.

6. Kazmi WH, Obrador GT, Khan SS, Pereira BJ, Kausz AT: Late nephrology referral and mortality among patients with end-stage renal disease: a propensity score analysis. Nephrol Dial Transplant 2004, 19:1808-1814.

7. Kessler M, Frimat L, Panescu V, Briancon S: Impact of nephrology referral on early and midterm outcomes in ESRD: EPidemiologie de I'Insuffisance REnale chronique terminale en Lorraine (EPIREL): results of a 2-year, prospective, community-based study. Am J Kidney Dis 2003, 42:474-485.

8. Metcalfe W, Khan $H$, Prescott GJ, Simpson K, MacLeod AM: Can we improve early mortality in patients receiving renal replacement therapy? Kidney Int 2000, 57:2539-2545.

9. Roderick P, Jones C, Drey N, Blakeley S, Webster P, Goddard J, et al: Late referral for end-stage renal disease: a region-wide survey in the south west of England. Nephrol Dial Transplant 2002, 17:1252-1259.

10. Roubicek C, Brunet $P$, Huiart $L$, Thirion X, Leonetti F, Dussol B, et al: Timing of nephrology referral: influence on mortality and morbidity. Am J Kidney Dis 2000, 36:35-41.

11. Schwenger V, Morath C, Hofmann A, Hoffmann O, Zeier M, Ritz E: Late referral-a major cause of poor outcome in the very elderly dialysis patient. Nephrol Dial Transplant 2006, 21:962-967.

12. Stack AG: Impact of timing of nephrology referral and pre-ESRD care on mortality risk among new ESRD patients in the United States. Am J Kidney Dis 2003, 41:310-318.

13. Danmarks Statistik. 2007. www.statistikbanken.dk Ref Type: Internet Communication.

14. Danish Nephrology Registry Annual Report. 2008. http://www.nephrology.dk/ Publikationer/Landsregister/Årsrapport\%202008.pdf. 2009. Ref Type: Internet Communication.

15. Andersen TF, Madsen M, Jorgensen J, Mellemkjoer L, Olsen JH: The Danish National Hospital Register. A valuable source of data for modern health sciences. Dan Med Bull 1999, 46:263-268.

16. Mosbech J, Jorgensen J, Madsen M, Rostgaard K, Thornberg K, Poulsen TD: The national patient registry. Evaluation of data quality. Ugeskr Laeger 1995, 157:3741-3745.

17. Nickelsen TN: Data validity and coverage in the Danish National Health Registry. A literature review. Ugeskr Laeger 2001, 164:33-37.

18. The Danish National Board of Health. http://sst.dk. 2010. Ref Type: Internet Communication.

19. Ref Type: Internet Communication. 2010. http://www.laegemiddelstyrelsen.dk.

20. Danish National Registry Report on Dialysis and Transplantation in Denmark. 2007. www.Nephrology.dk. 2007. Ref Type: Internet Communication.

21. Levey AS, Coresh J, Greene T, Stevens LA, Zhang YL, Hendriksen S, et al: Using standardized serum creatinine values in the modification of diet 
in renal disease study equation for estimating glomerular filtration rate. Ann Intern Med 2006, 145:247-254.

22. WHO Colllaborating Centre for Drug Statistics Methodology. 2010. http://www. whocc.no/. 2010. Ref Type: Internet Communication.

23. Danmarks Statistik. Indvandrere i Danmark 2008. 1-220. 1-12-2009. Danmarks: Statistik/ParitasDigitalPrint. Ref Type: Generic; 2009.

24. Hommel K, Rasmussen S, Kamper AL, Madsen M: Regional and social inequalities in chronic renal replacement therapy in Denmark. Nephrol Dial Transplant 2010, 25:2624-2632.

25. Wauters JP, Bosson JL, Forneris G, Turc-Baron C, Golshayan D, Paternoster G, et al: Patient referral is influenced by dialysis centre structure in the Diamant Alpin Dialysis cohort study. Nephrol Dial Transplant 2004, 19:2341-2346

26. Winkelmayer WC, Glynn RJ, Levin R, Owen WF Jr, Avorn J: Determinants of delayed nephrologist referral in patients with chronic kidney disease. Am J Kidney Dis 2001, 38:1178-1184.

27. Jungers P, Zingraff J, Albouze G, Chauveau P, Page B, Hannedouche T, et al: Late referral to maintenance dialysis: detrimental consequences. Nephrol Dial Transplant 1993, 8:1089-1093.

28. Krasnik A, Hansen E, Keiding N, Sawitz A: Determinants of general practice utilization in Denmark. Dan Med Bull 1997, 44:542-546.

29. Caskey FJ, Roderick P, Steenkamp R, Nitsch D, Thomas K, Ansell D, et al: Social deprivation and survival on renal replacement therapy in England and Wales. Kidney Int 2006, 70:2134-2140.

30. Chen SC, Hwang SJ, Tsai JC, Liu WC, Hwang SC, Chou MC, et al: Early nephrology referral is associated with prolonged survival in hemodialysis patients even after exclusion of lead-time bias. Am J Med Sci 2010 339:123-126.

31. Obrador GT, Ruthazer R, Arora P, Kausz AT, Pereira BJ: Prevalence of and factors associated with suboptimal care before initiation of dialysis in the United States. J Am Soc Nephrol 1999, 10:1793-1800.

32. Hommel K, Rasmussen S, Madsen M, Kamper AL: The Danish Registry on Regular Dialysis and Transplantation: completeness and validity of incident patient registration. Nephrol Dial Transplant 2010, 25:947-951.

doi:10.1186/1471-2369-13-108

Cite this article as: Hommel et al:: The importance of early referral for the treatment of chronic kidney disease: a Danish nationwide cohort study. BMC Nephrology 2012 13:108.

\section{Submit your next manuscript to BioMed Central and take full advantage of:}

- Convenient online submission

- Thorough peer review

- No space constraints or color figure charges

- Immediate publication on acceptance

- Inclusion in PubMed, CAS, Scopus and Google Scholar

- Research which is freely available for redistribution 